\title{
Gender, Migration and Development: Can Advocacy Groups Be More of a Hindrance than a Help?
}

\author{
Sally Shortall ${ }^{1}$ and Ruth McAreavey ${ }^{2, *}$ \\ 1 Centre for Rural Economy, Newcastle University, Newcastle NE1 7RU, UK; Sally.shortall@ncl.ac.uk \\ 2 School of Geography, Politics and Sociology, Newcastle University, Newcastle NE1 7RU, UK \\ * Correspondence: ruth.mcareavey@newcastle.ac.uk
}

Academic Editor: Rebecca R. Scott

Received: 28 November 2016; Accepted: 9 May 2017; Published: 13 May 2017

\begin{abstract}
The social world is complex and ever changing. However, to function, we need shared common knowledge for social relations and social interaction. We need categories of people, and assumptions about collective identities. While this is necessary to manage social interaction, it also leads to debates that question the essentialism of collective attributes and identities. In this article we argue that advocacy groups campaigning for the rights of women and migrants can sometimes reinforce an understanding of these groups as static and unchanging and this impedes their development. The article contends that advocacy groups, can, unintentionally, reinforce stereotypes. Two different data sets, both drawn from Northern Ireland, are used to explore this question. Our case studies raise global questions about the need for critical analysis and reflection on the strategies used by advocacy groups to advance social equality.
\end{abstract}

Keywords: advocacy groups; women; migrants; essentialism; policy; inequalities

\section{Introduction}

It is generally recognised that advocacy groups are often important advocates of human rights and can regulate and moderate unfair practices (Skocpol 2004; Chetkovich and Kunreuther 2007; Mosley 2012). In this article we are interested in the power of advocacy to shape the understanding of social 'problems' and discriminated against groups. Social relations have a spatial and temporal referent; they are constructed in some physical location and at a particular time (Brewer 2013). This of course also means that social relations, norms, and positions in society change over time. We argue that advocacy groups, in order to advance their case, can present an understanding of groups of people as if they have an underlying and unchanging 'essence'. A 'sameness' amongst the group is implied, and it focuses on stasis more than social change. In this article we examine two groups that we argue are described in essentialist terms by advocacy groups which in turn impacts on policy and legislation: rural women and migrants.

We are interested in the social processes that contribute to the continuance of a static, unchanging representation of particular social groups, and in this article we examine two social processes. First, we look at the tendency by advocacy groups to present the world in terms of binaries (either $\mathrm{x}$ or $\mathrm{y}$ ) and how this presumes that each group is homogeneous. Previous research has shown that it is easier to construct social policies in terms of binaries, even though it minimises the complexities of social reality and overlooks diversity within each group (Saraceno 2013). Second, we argue that the power of advocacy groups, and their ability to present static representations of social groups is heightened when equality strategies are poorly thought out; when there is a weak political commitment to them or when organisational survival becomes the core mission of advocacy groups. In these instances, the policy focus is on procedure rather than substantive outcomes, and in such cases, we further argue that there is scope for advocacy groups to gain additional influence in the policy process. We suggest 
that an approach to policy which focuses on procedures rather than substance are not only taken when there is disagreement about power arrangements or objectives (Radaelli and Meuwese 2010), but also when there is a public responsibility to be seen to tackle a social issue, but there is no real political commitment to do so. This type of situation can give advocacy groups a powerful position within the policy making process.

The article is structured as follows; it begins with a discussion of what we mean by essentialism and its value as an analytic tool. Next is a brief overview of the role of advocacy groups and their source of social power. Then we present our case studies. We look at the situation of rural women and migrants in Northern Ireland. We start with a brief overview of the legislative framework in Northern Ireland, one where the political history affords advocacy groups a central role in policy making. Next we present our methodologies, and then the two case studies. We conclude that as long as we have policies without real political commitment, and policies that engage in and encourage binaries, essentialist categories will be assigned to groups of people. This is problematic, as it promotes a world view of groups of people which may be outmoded and no longer reflects the lived experience of groups of people. It can lead to social interaction which presumes the sameness of a group, rather than recognising diversity.

\section{The Trouble with Essentialism}

The literature on essentialism is vast. It is hotly debated by, amongst others, sociologists, psychologists, anthropologists, philosophers and educationalists. It is a much contested concept, and here we limit our review to explain why strategic essentialism, although rejected by many, provides a useful conceptual lens. In contrast to constructivism, which asks how we arrive at particular identities, essentialism considers what it means to have that identity (Berg-Sørensen et al. 2010). While for some essentialism is a slur word e.g., (Hacking 1999), others point to the fact that the creation of the binary of essentialism-constructivism is equally problematic (Phillips 2010; Fuss 1989). Accepting one over the other can impede innovative thinking and remove the need for critical reflection (Fuss 1989). Moreover, even if essentialism is analytically limited not least because it does not accommodate the way in which identity is constantly being renegotiated, it does not mean that it should be dismissed outright: sometimes it can provide 'politically necessary shorthand' (Phillips 2010, p. 47).

Essentialism assumes that people have an underlying and unchanging essence. They share essential characteristics that are assigned prior to social interaction (Narayan 1998; Baumann 1996; Massey 2004). Often this essentialism is given according to gender, culture and race. It is the basis of stereotyping, and social interaction is shaped by essentialist beliefs about particular social groups. Essentialism gives undue weight to biological or physiological explanations rather than sociological or cultural ones for human behaviour (i.e., women are more passive than men). Essentialist categories pay little attention to the spatial and temporal nature of society; that is, the fact that people and groups are understood and socially constructed differently in different cultures and at different times in history. The use of essentialist categories to define migrants and women is well researched (Massey 2004; Nussbaum 1995; Danius et al. 1993; Eide 2010; Spivak 1985; Spivak 1988; Stone 2004; McAreavey 2012; McAreavey. forthcoming; Shortall 2014). One particular aspect of this debate that is of interest when we come to examine how lobby and advocacy groups use essentialism, is the idea of strategic essentialism.

The concept of strategic essentialism (or the strategic use of essentialism) is very much associated with Gayatri C. Spivak (Spivak 1985; Spivak 1988). The strategic use of essentialism shows that members of an ethnic or minority group, while recognizing that they are internally diverse, downplay this publicly and instead present themselves in a homogeneous or 'essentialised' way, often playing to a stereotype of the group. This is undertaken for strategic reasons, to achieve particular goals. Eide (Eide 2010, p. 76) argues that strategic essentialism, advancing group identity in a simplified way, allows the possibility of this being manipulated by more dominant groups for their own ends. Another danger is that the experiences of all of that group are read off the specificities of one sub-group (Danius et al. 1993). Stone questions how realistic it is to try and achieve political goals on the basis 
of claims that do not represent social reality as it is constantly changing. Indeed Danius et al. (1993) have 'given up on it' as a phrase. But it retains value as an analytical tool (Danius et al. 1993, p. 35) even if its deployment is ultimately wrong. Baumann (1996) shows how social reality is constantly changing and it can differ for different groups. Examining the use of ethnic categories in London he discovered that the way in which categories were deployed by politicians and policymakers did not reflect a changing social reality. Many younger residents were building a new identity that cut across existing religious and ethnic boundaries. Even though the 'old' categories were problematic because they failed to attend to the complexities of emerging identities, their application in everyday lexicon and within social structures constitute a social reality (Phillips 2010; Baumann 1996). We endorse Phillips' belief that there are times when we need 'to 'take the risk of essence' in order to have any political purchase' (Phillips 2010, p. 48). Mindful of its limitations, we show how strategic essentialism remains a social reality and the way in which it is deployed warrants our attention. Much attention is drawn to the damaging effect of the imposition of essentialism from within a group. We show how it is used by agents both external and internal to the group for other, often questionable purposes. We argue that advocacy groups seem to use essentialist views for strategic reasons, and an unintended outcome is that it can create a distorted and static interpretation of social reality.

\section{Advocacy Groups and Power}

Weber, in the 1920s, identified the power of focused groups ('Party') with particular objectives to influence decision making processes. He saw these groups occupying the house of power, or politics. Their objective is to influence decisions and actions implemented by those in power, and in this way they exercise their power (Gerth and Mills 1946). To this day, it is recognized that effective lobbying by interest groups can be far more influential in shaping policy than 'robust' evidence (Shortall 2012). If a policy stance is politically unpalatable then regardless of the evidence it is unlikely to be implemented because ultimately, politicians want good press and re-election (Monaghan 2009; Monaghan 2010). In turn advocacy has increasingly become part of the raison d'être for many third sector organisations (Guo 2007).

Currently, the ability of lobby/advocacy groups to shape policy is heightened (Shortall 2012; Shortall 2013). This is because of a growing demand for, and commitment to, greater public participation in scientific decision-making and policy formulation (Martins and Richards 1995). Moving beyond technical expertise to include experiential expertise is seen to enhance political legitimacy. Stakeholders and lobby groups contribute essential expert and experiential knowledge about complex policies and programmes. These groups often have detailed knowledge of how policies roll out in practice and they can contribute in-depth knowledge of the different impact of those policies in particular situations. Engagement with those who formulate the policy, who carry it out, and who experience its effects becomes a crucial component of understanding public policy.

Clearly advocacy groups are not homogenous. Their funding arrangements vary; they differ according to organisational structure, scope of activities and they operate differently (Skocpol 2004; Guo and Saxton 2010; Mosley 2011). While the meaning of civil society is contested, there is agreement that it is seen as including the multitude of associations around which society voluntarily organizes itself and which represent a wide range of interests and ties. These can include community-based organizations, indigenous peoples' organisations and non-government organizations (Roginsky and Shortall 2009; Organisation for Economic Co-Operation and Development 2006). Two general types are relevant to this paper: professional organisations dependent on government (NGOs) and other non-profit bodies including smaller grass-roots organisations reliant on private donors (often community and church based). The rise in professionally managed bodies that has been visible in recent decades is often accompanied by the employment of managers and graduates who have strong affiliation with policymakers (Skocpol 2004) who deploy certain advocacy tactics including becoming 'insiders' by aping and amplifying the institutional norms and values of government (Mosley 2012; Guo and Saxton 2010; Mosley 2011). As a result these groups 
develop insider connections, they are less adversarial than in the past, they work in 'partnership' with government all of which institutionalises advocacy (Mosley 2012; Gormley and Cymrot 2006). A close relationship with government is essential for those groups' survival as they rely on core funding streams and this can mean that the apparent central mission of the organisation (working with users) takes second place (Mosley 2012) or it becomes just as important (Guo 2007). Mosley (2012) also persuasively argues that the field level norms of advocacy have also likely changed due to the overall increased reliance on government funding. Alternatively, for groups that rely on private donors, they are less motivated to spend time advocating on policy, engaging instead in front line service delivery (Chetkovich and Kunreuther 2007) and using more adversarial advocacy tactics such as 'fighting' with government officials (Mosley 2012, p. 19).

We want to further argue that when governments and policy makers state a commitment to mainstreaming or implementing a policy to which there is little real commitment, the power of advocacy groups is increased. We argue this is because politicians are judged on how effectively they deliver on policies. Advocacy groups linked to stated policy commitments to advance equality for particular groups are well positioned to put high profile pressure on government to deliver on their commitment. For government, demonstrating that they have done so will appeal to their wider constituents and help to legitimize policy choices (Boswell et al. 2011). We argue that in some instances a circular logic emerges; government funding of these advocacy groups becomes evidence of a commitment to equality, and this maintains the focus on procedure rather than substance. The power of advocacy groups to do this is facilitated by the development of policies to which there is a weak political commitment or where there are few advocacy groups operating in a particular area. We now turn to the policy context of our case studies to frame the findings to come.

\section{Northern Ireland and Equality Legislation, and the Case of Gender and Race}

As part of the EU, Northern Ireland is bound by European Law. Equality and non-discrimination are complex concepts, with considerable debate on their meanings and justification. The discussion of equality and discrimination is, in general, characterised by considerable conceptual and methodological confusion. This is no different at the EU level. In addition, legislation and directives roll out differently in different places and national legislation is important in how equality frameworks are designed and implemented. While EU law affects practice in Northern Ireland, the most important piece of regional legislation is Section 75. Following on from the Good Friday Agreement ${ }^{1}$, very progressive equality legislation was developed. Although borne out of traditional political and religious tensions between Protestant and Catholics, it places positive duties on public authorities to have due regard for the promotion of equality of opportunity more broadly ${ }^{2}$. In 2010, the Equality Commission published new statutory guidance on Section 75 of the Northern Ireland Act 1998 for public authorities. The Commission recommended a changed approach to equality mainstreaming, focusing on the identification of inequalities and the development of measurable and time-bounded actions to address the inequalities identified. This mainstreaming approach attempts to address institutional forms of discrimination ${ }^{3}$. It imposes a statutory duty on listed public authorities in Northern Ireland to generate an approved equality scheme, and to carry out equality impact assessments on all new and existing policies. One of the strengths of Section 75 is the requirement that this must be done in consultation. It has received some favourable reviews in policy circles both for its insistence on

\footnotetext{
Northern Ireland Act 1998 (Appointed Day) Order 1999. Multi-Party Agreement, Declaration of Support, Paragraph 2.

Section 75 of the Northern Ireland Act 1998 requires public bodies when carrying out their work to have due regard to the need to promote equality of opportunity between nine categories of persons: Between persons of different religious belief, political opinion, racial group, age, marital status or sexual orientation; between men and women generally; between persons with a disability and person without; and between persons with dependents and persons without.

3 Ethnic minority advocacy groups argue that this is not sufficiently effective and they seek reform of the racial equality legislation, see discussion below.
} 
a participatory-democratic model and the relative sophistication of the model of equality impact assessment that is used.

One implication of Section 75 is that it gives a very powerful role to advocacy groups to influence policy ${ }^{4}$. Northern Ireland has a long and well-established vibrant community and voluntary sector. The UK has supported many NGOs and the sector provides considerable employment in the region. During the thirty years of Direct Rule, the voluntary and community sector participated in the governance of the region to a degree that is unusual, if not unknown, elsewhere (McCall and Williamson 2001, p. 364). Consultation with stakeholder groups is deeply embedded in the political culture as it was seen as a way around the democratic deficit in the region (Hasenfeld and Gidron 2005; Knox 1996). More recently, the development of Northern Ireland's equality mainstreaming approach requires by statute, consultation with stakeholder and civic groups in the policy development process. The practical implications of this are that designated public authorities are required to establish relationships with civic actors and groups, who are then treated as equality 'experts' to be consulted on policy developments (Donaghy 2004). This means that in Northern Ireland there is a formal and interactive relationship between civic society and government. The political context is favourable to stakeholder engagement in policy formation, and experiential expertise of the impact of policy is seen as a key form of evidence informing the development of policy (Shortall 2012; Shortall 2013).

However the broader commitment to equality is often nebulous and unclear. The focus is often on procedure rather than outcomes. How mainstreaming is approached is illustrative of commitment in practice. Radaelli and Meuwese (2010) consider the difference between the textbook rationale for impact assessments (IA), and how they are actually implemented. While in theory IA is supportive of decision-making processes, in practice it is poorly implemented. Why is this? Radaelli and Meuwese (2010) argue that certain procedures and instruments are chosen by policy-makers when there is disagreement on fundamental issues of power. Instruments are chosen that simply make IA degenerate into tick-the box routines and disappear from the political radar. Often the IA is all about procedure and avoids as far as possible references to substance (Radaelli and Meuwese 2010). They further argue that for the European Commission, which is a political organisation rather than an action-driven organisation, to be seen to make 'decisions' counts more than the 'actions' taken. How it works out in practice matters less than the decision. We want to take this argument further and contend that tick-box approaches, and a focus on procedure rather than substance, also emerges when there is a lack of political commitment to a particular policy objective. We will argue that far from advancing equality, attempts at mainstreaming revert to defining groups in disadvantaged, essentialist ways. This focus on procedure, we argue, is because there is a very low political commitment to achieving the stated policy objectives. Implementation is perceived to occur by training civil servants to understand procedures such as completing appropriate forms, without any consideration of what the substantive achievement of equality might look like. We now argue that this process allows advocacy groups to assume a disproportionate amount of power in the policy process, and that their actions can further essentialise understanding of particular groups of people.

\subsection{Gender, Rural and Legislation}

Gender mainstreaming is an obligation under European legislation (Commission of the European Communities 2005). It states that: Member States and the Commission shall promote equality between men and women...this includes the stages of design, implementation, monitoring and evaluation (Commission of the European Communities 2005, Article 8). Equal opportunities were to be integrated into all programmes and actions, ex-ante evaluations of future national plans were to include a gender assessment, indicators were to be broken down by sex, and the composition of committees at national,

4 This is also true at the EU level (See (Shortall 2014)). 
regional and local level were to take account of the need to promote equality between women and men. However, there is little evidence to suggest this actually happened. In the case of Northern Ireland, Section 75 requires that all new and existing policies are screened to ensure they do not have an adverse impact on any of the named groups, including women. In terms of rural development, the Equality Unit in the Ministry of Agriculture and Rural Development ${ }^{5}$ train and advise the Ministry on how to comply with equality legislation.

\subsection{Migration, Racial Equality and Legislation}

Two key areas of legislation and governance impact directly on migrants in Northern Ireland. Legal status is governed by International, European and UK migration law and it is from these sources that migrants' perceived legitimacy to exist in a particular area is derived. Additionally, they are also afforded protection from a rather complex interplay of equality legislation that includes Section 75 and Race Relations.

Regarding equality legislation and similar to gender equality, racial equality measures are legally embedded in the Treaty of Amsterdam. Various directives since allow the EU to take appropriate action to combat 'discrimination on grounds of sex, racial or ethnic origin, age, disability, sexual orientation, religion or belief (Commission of the European Communities 2008, p. 2). Race Relations legislation in Northern Ireland ${ }^{6}$ was amended in 2003 and again in 2009 to give effect to the EU Racial Equality Directive. The Order outlaws discrimination on racial grounds. Racial equality is also addressed through Section 75. It denoted an important shift from community relations to a broader one of fostering 'good relations' between different social groups. This change marks an attempt to overcome essentialised approaches to the conceptions of community that persisted for a long time in the region. In reality policy interventions do not align with this more inclusive vision.

\section{Methodology}

While both authors found evidence of legislation and advocacy groups socially constructing an understanding of migrants and rural women as less capable, this was not the focus of either of the research projects. McAreavey uses data from research that she has been conducting with migrant communities in Northern Ireland since 2005. The objective was to identify links between poverty and ethnicity. A series of 13 focus groups and 43 interviews were conducted with migrants and with support agencies between 2005 and 2013 (see (McAreavey 2012; Irwin et al. 2014; Wallace et al. 2013) for further information). With consent all were taped, transcribed and anonymized. Access to respondents was initially gained through a gatekeeper working with an advocacy group. Research participants were paid an honorarium. The research was conducted in three locations, Belfast and two rural areas of Northern Ireland. Both rural areas had experienced a significant increase in migrant communities following the expansion of Europe in 2004. Most participants were recent arrivals, although some had been living in Northern Ireland for at least twenty years. Participants were from Eastern Europe, Asia and Africa and included professionals as well as individuals working in unskilled jobs, many of whom held multiple jobs. The research design did not focus on a specific nationality, age-group or define a particular socioeconomic profile. However, many of the focus groups and interviews were conducted with the Polish community, the largest Eastern European group in Northern Ireland (Northern Ireland Statistics and Research Agency 2013). Transcripts were coded according to emerging themes and these were discussed within the relevant research teams and corresponding advisory groups. Initial findings were presented to migrants and advocacy groups and following those discussions, further data coding and analysis was conducted. Subsequently

5 This department has since been renamed Department of Agriculture, Environment and Rural Affairs.

6 Race Relations (NI) Order 1997. 
final project findings were presented in various fora which included interactive sessions that were subsequently written up. Findings presented in this article are representative across the sample.

The focus of Shortall's research was to consider how women engage with the European Rural Development Programme (RDP). The European Commission and the European Parliament have specifically expressed concern about the differential gender impact of the rural development programmes across Europe. The research was conducted between 2012 and 2013. Thirty-six interviews were conducted, and with consent, taped and transcribed. Interviews were purposive and semi-structured and were conducted with people in Divisions within the Department of Agriculture and Rural Development as the managing authority for the RDP, the Rural Network in the region, women's sector organisations, Local Action Groups who manage delivery, NISRA who conducted the mid-term evaluation, the Equality Commission, and farming groups. Seven focus groups were carried out; two focus groups with women on farms, two with women involved in rural development, one with a rural women's group not attached to the rural development programme, one with men on farms, and one with a Men's Sheds group. Focus groups had between eight and fourteen participants.

\section{Findings: The Case Studies}

\subsection{Case Study One: Gender, Policy and Advocacy Groups}

In Northern Ireland, the 2007-2013 rural development programme in Northern Ireland was worth approximately 540 million pounds. The Ministry of Agriculture and Rural Development (DARD) was the 'managing authority' and had responsibility for the management and implementation of the Rural Development Programme. There was also a Programme Monitoring Committee for the NIRDP which is responsible for overseeing the effective implementation of the programme. It was chaired by a representative of DARD and includes representation from: the economic and social partners; competent regional, local and other public authorities; and other appropriate bodies non-governmental organisations representing civil society (including environmental organisations and those responsible for promoting equality). The European Commission also participated in the work of the NIRDP Monitoring Committee in an advisory capacity. One responsibility of the monitoring committee was to ensure that equality considerations underpinning the delivery of the Programme were delivered. There is also a sub group which specifically focuses on Equality and Good Relations. Both the EU and regional commitment to gender mainstreaming must be observed, and women were identified as a target group for the RDP. However, how gender equality objectives or targets are linked to gender mainstreaming is not clear.

The Mid-Term Evaluation Report of the most recent programme (Northern Ireland Statistics and Research Agency 2010) raised concerns about the limited evidence to date that the potential inequalities highlighted in the Programme Equality Impact Assessment (EQIA) had been actively addressed. The evaluation specifically noted that there was little evidence of targeting of women in the current programme, and recommends that DARD actively engage with the rural women's network, an advocacy group long funded by DARD, to use their expertise to reach this target group to promote the programme (Northern Ireland Statistics and Research Agency 2010, p. 5). They consulted with the rural women's network before making this recommendation. Time and again the evaluation stated the need to do this. It recommends that DARD considered the need to target women as a priority, but it does not suggest how this might be achieved, or identify any targets. The mid-term evaluation also noted that it was difficult for the monitoring committee to monitor when there is very little monitoring information. They also raised some concerns about conflicts of interests of members on the monitoring committee who promote particular aspects of the programme in line with their organisational interests.

\subsubsection{The Dual Narrative: Essentialism and Social Change}

Ever since the first Rural Development Programme, there has always been a specific focus on women, with the taken for granted assumption that they constitute a disadvantaged group. The 
Ministry of Agriculture and Rural Development has funded various initiatives to address this issue of gendered disadvantage including a rural women's network. There is an essentialist view of women as disadvantaged and immobile. The rural women's network has on the one hand, a vested interest in perpetuating this view, because it keeps gender as a current issue and legitimizes their existence and funding. However, there was evidence of a tension between the static essentialist idea that women in rural areas project as disadvantaged and immobile, while at the same time, having to acknowledge social change. For example, one woman from the rural women's organisation displayed this tension in her interview:

Childcare and transportation would be the two biggest barriers...if there's only one car in the household and you're in a rural area that means you're effectively stuck in that area until your car becomes available, and that's presuming you can drive. The other thing that is a major issue is timings of meetings and things like that so, you know, if there's a meeting from 2-4 of their Local Action Group, they maybe have to organise somebody to collect their children, look after their children, you know, there's a lot of issues to just even getting to a two hour meeting.

This is very much a static essentialist view of rural women that is commonly promoted by advocacy groups; women in rural areas are less mobile, less visible in public space, and have less access to childcare. There is also the assumption that if there is a car in a household, it will be the man who has first claim on it, even though previous research in Northern Ireland found this not to be the case (Shortall and Kelly 2001). There is no quantitative data used to substantiate this claim. Elsewhere in the same interview, the interviewee contradicts the essentialist view of women as non-participants due to disadvantage:

In an ideal world it would be that women have $50 \%$ representation on the governance of it...in representation I think, in maybe, equally successful, but I think, you know, some of that is achievable quickly and some of it not so quickly, I think the Local Action Groups and the fact that that stipulation came from Europe. If that hadn't have come from Europe we would still be...everybody would still be going 'ah but women are just not interested in sitting on committees', sure that's...we were told that all the time, yet, there they are, they have it, as best...I know it's not all totally perfect 50/50 but it's pretty good and I think, you know, that's bound to be making an impact, particularly in scoring projects and when people are saying what works, I think it's bound to help [emphasis added].

This last quote, that women are well represented in the Local Action Groups contradicts her earlier statement that childcare, transport and timing of meetings prevents women's participation. Women are occupying public space, but this is at odds with essentialist narrative which continues to portray women as excluded, and which justifies the existence of the rural women's network.

\subsubsection{Embedding Essentialism In Policy Objectives}

The Mid-Term Evaluation stated repeatedly that The Department of Agriculture and Rural Development needs to target women in the current Rural Development Programme 'who have historically had low representation in related activities' (Northern Ireland Statistics and Research Agency 2010, p. 86). Again, the essentialist view of women continues to be perpetuated after twenty-five years of repetition in rural development programmes. It is constantly repeated. The evidence on which this claim is made is not clear, and NISRA does offer caveats stating available data was not robust, and this was supplemented with interviews with key stakeholders, including the Rural Women's Organisation. In almost all the interviews, people found it hard to identify what an equality agenda was trying to achieve for rural women. For a senior figure in the rural women's organisation 'success' was keeping rural women on the agenda. 
The Mid Term Evaluation has highlighted women as a target group and we have, in addition to being on the steering group for the Mid Term Evaluation, and trying to ensure that women stayed (laughs) and stayed on that report as a target group, we have also been very instrumental in keeping, arguing and advocating for the fact that there needs to be a mechanism for targeting, it's not enough to say that women are a target group, and they are not accessing it, you know that's not sufficient.

This interviewee believes in separate measures, including funding of her organisation, but it is not clear to what end. Her objective is to ensure that women 'stayed on that report as a target group'. There is an essentialised homogeneous understanding of women as a group that need to be targeted and that need special measures. Repetition of this view of women has shaped policy objectives. The interviewee is clear that her organisation successfully advocated to have women recognised as a target group in the Mid-Term Evaluation. She later quotes the Mid Term Evaluation as evidence that gender inequality needs to be a policy priority;

Otherwise the Mid Term Evaluation wouldn't have been saying women are a target group.

And elsewhere:

No. (Laughs) No I don't. I...no, I don't think it...I think well, the fact that the Mid Term Evaluation identified (laughs) women as still being an issue, clearly it wasn't that successful.

In other words, having lobbied to have women recognized in an essentialist way in the policy document, she then quotes the policy as evidence of an essentialised understanding of women; if there was not an issue then the document would not have identified women as a target group, when in fact it was lobbying by her organization that perpetuated this understanding of women in the report.

\subsubsection{The Difficulties of Addressing Gendered Essentialism through Policy}

Public policy is tasked with addressing social inequalities and protecting the rights of vulnerable or excluded groups. As women are identified as one such group, then it becomes the responsibility of the Ministry of Agriculture and Rural Development to address this inequality. However, it becomes difficult to implement policies premised on an essentialist understanding of women's disadvantage, rather than having identified issues to address. Interviewees grappled with this issue, giving examples of problems that were addressed, and querying why it was not the same for gender issues. A director of a rural development organisation said:

If you look in any of the rural development programmes it has been highlighted that women are less represented...if that's an issue why was there not an initiative specifically designed to address that? They identified the issue around young farmers getting involved in farming so they set up a programme around new entrants.

SS: Why do you think there wasn't anything targeted at women?

Well a couple of things - one could be they had no appetite for it. The other is that it wasn't considered a priority.

What the interviewee is saying is that when there is a concrete problem identified, then it is possible to implement policy measures to address the issue.

The equality unit in the Ministry is responsible for ensuring that their policies comply with regional and European legislation, and address the gender inequality stated in their policy documents. The following is an extract from an interview with a person in the unit:

Interviewer: Do you know what data is currently being used to measure women's participation in the Rural Development programme. Like what are we using to say $x$ number of women are participating? 
No I am not sure.

Interviewer: In terms of the equality lessons from the current programme how would these be captured or shared either across the department or particularly what you need to carry onto future programmes?

I suppose NISRA would have a big role here because a lot of the equality monitoring forms go back to NISRA for analysis and they produce then a report that would come back to DARD then which should help feed into the next programme.

Interviewer: The engagement and participation of women in the current programme is identified as a problem and this was also identified as a problem in previous programmes. Do we have robust enough data to support that claim?

I don't know. I suppose there is probably merit in asking either NISRA or delivery people...I don't know...that might give you a better synopsis on that one.

There is no evidence to support the essentialised view of women as a disadvantaged group. It has become a 'fact' because it is constantly repeated. Because there is no evidence to support the problem, introducing meaningful policy measures is impossible. It is a policy objective with no basis in reality so it cannot achieve social change.

One employee of the Ministry of Agriculture and Rural Development involved in the design of the programme identified this problem of lack of evidence to support the idea that rural women are disadvantaged and need special measures. She commented on how policy priorities are created and maintained;

Is it because it's just kept in the public, you know if this research is needed to say if there is or isn't a problem, is it a historical issue that was there and you have lobby groups there that keep it in the public domain and without proving one way or the other whether it's an issue or not and that's difficult so until we find out for sure if it is an issue I would say like any lobby group will keep any aspect of the programme as an issue but you won't necessarily have the facts behind that, I mean it's not just women, it's disability, the environmentalist, the NGOs would be the same, any of them have their own interests within the programme and their lobbying will keep it as an interest unless something can prove that it's not actually an issue.

In other words, she recognizes that one of the difficulties for the programme is that lobby groups perpetuate essentialised understandings of the groups they represent. She sees that they have a vested interest in keeping their agendas in the public domain, and she also sees it as difficult to disprove some of these assumptions.

\subsubsection{Perpetuating Essentialism through Mutual Need: Policy Makers and Advocacy Groups}

The Ministry needs to consult with target groups to meet its statutory obligations around equality. One stated obligation is to address gender equality. As it is based on an essentialist understanding of women, it is difficult to address. Nonetheless, as long as it is a stated commitment, the Ministry must be seen to address the issue, and is vulnerable to calls from advocacy groups to do so. Funding the advocacy group can actually become a means of achieving this end. The equality unit see the rural women's network as central to their ability to address gender equality:

You know we need to hear the views of rural women, what their needs are, that's useful information for developing policies and the direction of where the department needs to focus. I think the main way the department will be able to get from where it is now to where it wants to be is working hand in hand with women's organisations from rural areas. Because they can reach out to women themselves they can see what the obstacles and the barriers are and they can help us reshape how we provide our services, how we hold our 
board meetings so that women are at the table. If women aren't there now they can tell us what we need to do in order to change it and then help get the women there.

The static essentialist view of rural women as facing obstacles and barriers is never questioned. The Ministry relies on the rural women's network, which they fund, to identify the problems that they need to address. This gives legitimacy to the essentialised view of women perpetuated by the rural women's network. For their part, the rural women's network sees their role as helping the Ministry develop and implement their targets.

We met with DARD Equality branch and we had like a one to one interview with them and we've also had them to the Rural Women's Policy Forum so they can engage with other people other than just us on that...I think, you know, going back to what the Department see as our role, you know, I think the Equality branch would see us as having a role in supporting them to actually, now they've got targets...how to help deliver those targets for them.

The essentialised view of women becomes embedded by the Ministry relying on the rural women's network to identify the policy issues they should address. The rural women's network point to their role in the policy process as part of their legitimacy for existence. Providing a static essentialist view of women is being used to shape the policy process and secure their own funding.

\subsection{Case Study Two: Racial Equality and Migrants to Northern Ireland: Background}

Being embedded in a place can generate resistance to diversity as it often provides frames of reference that focus on how things were in the past (Gimpel and Lay 2008). The prevailing tendency in Northern Ireland has been one of considering society by traditional binaries; Catholic/Protestant; Nationalist/Unionist; Republican/Loyalist. The strength of the conceptualisation of traditional binaries of community according to the two majority groups impacts on race equality legislation. It took over 20 years after equality legislation was passed in the UK for similar legislation to be enacted in Northern Ireland through the Race Relations Order ${ }^{7}$. One theory for this delay is that there was a perception that it would be construed as anti-sectarian legislation, and government wished to separate sectarianism and racism (Lewis 2006). More recent reform of the Racial Equality framework brings with it measures that have been welcomed by many lobby groups. Most importantly it proposes major reform of the Race Relations Order. This reform is strongly advocated by many groups as it would bring it in line with the unified approach of the Equality Act (Her Majesty's Stationery Office 2010) that is found in other jurisdictions in the UK and importantly it would include institutional discrimination (Wallace Consulting 2011; Equality Commission Northern Ireland 2011; Northern Ireland Council for Ethic Minorities n.d.). However many flaws have been identified not least is the timing of the consultation as one advocacy group has pointed out that the legal and policy framework has been operating without an underpinning strategy, making it difficult to realize racial equality and rights (Northern Ireland Council for Ethic Minorities n.d.). The Racial Equality Strategy further advances race relations and it envisages a society 'where people of minority ethnic backgrounds have a sense of belonging which is acknowledged and valued by people from all backgrounds' (Gimpel and Lay 2008, p. 28). Implicit in this is that a stable society exists in which there is a common sense of belonging, a matter that is not reflected in the region's recent history.

\subsubsection{Migrants, Advocacy Groups and Static Essentialism-The Struggles of Representations}

Creating binaries of migrants and the mainstream fails to acknowledge the nuances within and between migrant communities. Many factors intersect to form individual identity; ethnicity is but one

$7 \quad$ Race Relations (NI) Order 1997. 
aspect. There was evidence of reducing migrants to their ethnic status with black African migrants being directed by larger NGO support agencies towards work in care homes or in security positions:

Ruth: What do you think of the future for you and your husband and children?

No. 3: I don't know (laugh), I am looking for other jobs because I feel that I cannot be a pharmacist here in Northern Ireland. I contacted [employability initiative] and they said that you can work as a care assistant (laughter from the wider group), you can do a course in September.

Support worker: How can [employability initiative] try to say to someone that you should be a care assistant, they are all the same, the case worker in the job centre will say, you do this, you do that, but these people are all qualified.

No. 2: They tell you to change your way, the system gets you to change your way ... when I go to the job centre to find a job, they told me you can find a job in XXX, but I didn't study this, I want to find something similar to what I did.

No. 3: ... even if I found a job, even cleaning in a pharmacy, they are telling you to switch your career ... Cleaning, washing dishes, care home .... .

(Focus Group African migrants 15 June 2013)

The Employability Initiative was funded in part to deliver a course that trained migrants to work as care assistants. It was in their interests to direct individuals towards activities that would boost their income and sustain the organisation. They were helping to frame advocacy efforts. Conversely, a volunteer for a small grassroots ethnic minority group expressed concern over this scheme and the fact that just a few larger organisations had the 'ear' of government. He was frustrated about not being able to help frame advocacy efforts, a sentiment echoed by other migrant volunteers in very small organisations. A major problem with the example above is that it assumes that migrants are desperate for any job whatever their qualifications and it underplays other parts of their identity that are relevant to the labour market including aspirations, qualifications and experience. It provides a short term fix, but it obscures debate on other structural barriers to labour market entry and it sustains existing inequalities. Essentialism used in this way is a political tool, exploited by those external to the group to achieve a certain goal, in this case being seen to be recruiting migrants to a training programme. Here we also see government essentialising advocacy groups, assuming that they all represent the voices of many different migrants.

Unequal treatment was not confined to black African migrants as a professional Polish woman explains when describing a comment made by a colleague in her work:

'You should not be asking for more money ... you have come from Poland, you are lucky to have this job' (Interview \#9, female Poland, 13 June 2013).

This woman's Polish identity was more important to that colleague than her professional qualifications and the underlying assumption was that she did not have equal entitlement to the labour market, a matter that was repeated by many other respondents. This was partly due to the reluctance among many in mainstream society in Northern Ireland to see migrants as anything other than a temporary phenomenon:

I also think it's something to do with where we're at in terms of Northern Ireland and in terms of our systems and our understanding ... it's almost as if the people who are coming here are still visitors and the idea is that they are going to go home again and it's reflected right through the system... when [refugees] sign up at jobcentre plus or wherever they are not called in for interview in the same way as locals would be because the thinking is that it's easier to keep them on benefits than to train them. That's a real problem and I really do think that we haven't ... got our heads around the fact that people are here to stay ... (FG Advocacy and Support Agencies, 3 April 2012, No. 3) . 
Institutions interpreted that part of the essence of being a 'migrant' was to be a temporary worker. This meant that institutions treated them as unequal: they were not afforded the same type of service as others who were perceived to be 'local'. As a result their opportunities for accessing jobs were significantly curtailed.

\subsubsection{Objectives of and Commitment to Race Relations}

A hierarchy of priorities arises from separating issues of cohesion and integration and was manifest in funding allocated for associated activities. In 2015 the Minority Ethnic Development Fund had an annual budget of approximately $£ 1.1 \mathrm{~m}$ and this was the only dedicated fund for this purpose. But when compared to the annual budget for good relations (i.e., relations between the two majority communities: Catholics / Protestants) of $£ 9.87 \mathrm{~m}$ it is clear that this is a relatively low priority.

This lack of commitment was also evident in the Department of Employment and Learning's (DEL) free service for the recognition of overseas qualifications. It was initiated on the premise that equality could be advanced by equal access to the labour market and the service was offered to individuals across eight locations in Northern Ireland. The original pilot was delivered in 2012 and in the subsequent 2-year period it was accessed 823 times with the most demand for the service coming from Polish migrants. DEL noted inconsistencies in data recording, to the extent that is was claimed that the recorded statistics may not be a true representation of actual demand for the service (Irwin et al. 2014).

Indeed the lack of policy commitment to this service and thus to wider issues of equality was further revealed by the fact that, while some employers were aware of the service, others conducted their own checks. Other employers simply did not recognize overseas qualifications as this Polish woman explained:

I also applied for other work, I was a temporary worker in a factory and they refused me because they thought my mathematics was very poor and they did not recognize my Polish qualifications.

This woman soon discovered that going through the process of having her qualifications recognized was no guarantee of certainty:

Yes, but it takes [process of having qualifications recognised] 6 months and then they said they think that it might be something like that, but they were not sure. Then when I took it to my interview they said that I had to get it done properly and that costs money.

(Interview \# 1, female Poland, 20 June 2013)

Implementing objectives without commitment can be harmful. The lack of monitoring and evaluation of DEL's initiative, both in terms of its credibility among employers and in relation to its impact on the employment pathways of the targeted group, demonstrates a tokenistic and piecemeal approach to equality in Northern Ireland. Employing an extemporised approach suggests that policymakers place more value on being seen to be taking particular actions than over the actual impact of those actions. The initiative to recognise overseas qualifications is not just an empty action. It is more harmful and has the counter effect of creating the impression that migrants' equality in the labour market is appropriately addressed, leaving migrants who are unable to access employment with few support structures.

\subsubsection{Relationship between Policymakers and Advocacy Groups: The Power of Advocacy Groups}

As already noted, part of the challenge in implementing a racial equality agenda in Northern Ireland is that it has not been a priority for policymakers in the past because sectarian divisions have been a political priority. However largely because of increased diversity, pressure on policymakers to instigate reform increased (Equality Commission Northern Ireland 2011; Northern Ireland Council for Ethic Minorities n.d.). 
The Northern Ireland Executive is responsible for implementing racial equality policy in Northern Ireland, specifically the Racial Equality strategy. It is advised by a Racial Equality Subgroup which comprises 'mainly people working with, or representing, minority ethnic people and migrants' (The Executive Office 2015, p. 10).

The Northern Ireland Executive is responsible for monitoring the progress of the Subgroup and in turn it reports progress to elected representatives. All sorts of advocacy, lobby and support agencies are tightly bound up in implementation processes (often in partnership with government), some are grass roots organisations reliant on volunteers, others are professionals who have a vested interested in sustaining their oganisation. This raises questions about how these different groups will be empowered and motivated to scrutinise activities with which they may have indirect involvement and it reflects the shift from an adversarial relationship towards one of friendly persuasion (Mosley 2012). Many of the Subgroup members are from professional NGOs and are in receipt of funds from The Executive, via streams such as the Minority Ethnic Development Fund or mainstream funding. There are relatively few other such organisations solely focused on racial equality, albeit this is a growing field with numerous very small grassroots organisations who are reliant on volunteers to deliver front line services and typically do not have the capacity to engage with policymakers. It means that government is reliant on just a handful of groups, typically larger NGOs, to help implement the strategy. The position of those agencies was not unnoticed and one health advocate commented:

Voluntary organisations, they are so precious about what they do and who does it, they are extremely territorial. There are different groups who should be working together in a multi-cultural way. There are many common issues and how they can be dealt with might differ slightly, but the services available are the same. So unless the services change, the difficulties and the solutions will be the same (Interview \#14, Health Advocacy Professional, 19 January 2010).

This individual identifies one of the problems that arise from essentialising, that of 'replicating' the very inequalities that those advocacy groups set out to overcome. The symbiotic relationships between policymakers and advocacy groups risked compounding struggles of representation, doing little to address structural weaknesses. This is exemplified by the emphasis on ethnic monitoring in the strategy which is something for which NGOs lobbied. Monitoring is at the core of the strategy. While there is no doubt that ethnic monitoring is essential to uncover inequalities in the region (The Executive Office 2015), it remains unclear if this will be interpreted as a managerial 'tick-box' exercise with little impact on the causes and consequences of inequalities. After all, the service to recognize overseas qualifications was monitored, but it did little to address structural inadequacies that failed to allow migrant incorporation into the labour market. Minimal information is provided on how the monitoring policy objective has the scope to shape the policy agenda, but policy makers can demonstrate a direct response to previous criticism from advocacy groups.

\section{Conclusions}

In this article we offer two case studies which we argue demonstrate that advocacy groups can represent static outmoded views of the groups they represent. Advocacy groups themselves are not all the same; they have different ways of operating and their objectives may not always correlate directly with all individuals within the group that they purport to represent. Here we see that rural women's groups presented women as being less well represented in governance structures than they knew to be the reality, and they deliberately manipulated the policy process to maintain this static unchanging representation. In doing so, the 'problem' of rural women stays on the agenda, and the legitimacy for their continuation as an advocacy group remains. Similarly, the way in which race legislation is designed in Northern Ireland presumes a homogeneous group of migrants who are all similar; unskilled and present in a short-term, transient fashion. The reliance by policymakers in Northern Ireland on just a few large NGOs further essentialised migrants. Moreover, migrants' 
voices are interpreted by intermediary professionals who may not be in touch with their needs as some advocacy efforts were framed by large NGO's beyond the confines of those communities and resulting in minimal accountability to different migrant groups. The diversity of these people and what they can contribute to society is brushed aside and flawed social structures are replicated. This is particularly damaging for migrants as their interests were considered to be represented by the inclusion of legitimate NGOs.

There is, for many good reasons, increased inclusion of advocacy groups in the design, implementation and evaluation of the policy process. However, this also brings responsibilities, and the actions and motivations of these groups must be considered in the same way as are those of the public and private sector. We argue that the power of certain advocacy groups is heightened in situations where there is a public imperative to be seen to tackle some inequality, but there is little political appetite to do so. The way 'to be seen' to be doing something is to focus on process and ticking boxes, rather than trying to achieve evidenced outcomes to improve a situation of inequality. In this context, there is political vulnerability as advocacy groups can pressurise for particular outcomes that are more aligned to their institutional longevity than their ideological mission. In these circumstances the potential for social change is jeopardised. More knowledge is needed on how different types of advocacy groups juggle institutional demands with advancing social change.

Northern Ireland is a particular case and advocacy groups are central to the policy making process. But it is not unusual either, and this is increasingly the case, both in the global North and South. Perhaps then it is time for government and civil society to reconsider the diversity of advocacy groups and how organisational sustainability and meaningful social change can both be achieved. Further scrutiny could also be directed towards the accountability of advocacy groups and the degree to which communities are present in framing advocacy efforts.

Promoting a world view of groups of people which may be outmoded and no longer reflects the lived experience of groups of people, is problematic for a number of reasons. First it tends to present an image of groups which emphasises the sameness of a group, rather than recognising diversity. Second, it overlooks real, important and positive processes of social change. Finally, it also focuses policy on issues that may no longer be the key goals or that may not have scope to address structural weaknesses, and thus diverts attention and resources from the questions that should be of social concern. This is a question that we believe warrants further attention, and that would benefit from comparative analysis.

Acknowledgments: Shortall's research was funded by the Economic and Social Research Council: ES/JO1031/1 'Gender Mainstreaming the Rural Development Programme'. McAreavey's research was funded by the Nuffield Foundation's Small Grant Scheme REF SGS/34428 and the Joseph Rowntree Foundation (REF: 1103001A; Ref: 1103001PFA01). No funds were provided for open access publications.

Author Contributions: Sally Shortall and Ruth McAreavey conceived the idea for this project through various informal discussions. Sally Shortall conducted the research relating to rural women and Ruth McAreavey the research on migrants. They both wrote the introduction, literature review, the methodology and the conclusions. Sally Shortall wrote Sections 4.1 and 6.1 and Ruth McAreavey Sections 4.2 and 6.2.

Conflicts of Interest: The authors declare no conflict of interest. The founding sponsors had no role in the design of the study; in the collection, analyses, or interpretation of data; in the writing of the manuscript, and in the decision to publish the results.

\section{References}

Baumann, Gerd. 1996. Contesting Culture: Discourses of ldentity in Multi-Ethnic London. Cambridge and New York: Cambridge University Press.

Berg-Sørensen, Anders, Nils Holtug, and Kasper Lippert-Rasmussen. 2010. Essentialism vs Constructivism. Distinktion: Scandinavian Journal of Social Theory 11: 39-45. [CrossRef]

Boswell, Christina, Andrew Geddes, and Peter Scholten. 2011. The role of narratives in migration policy making a research framework. British Journal of Politics and International Relations 13: 1-11. [CrossRef]

Brewer, John D. 2013. The Public Value of the Social Sciences: An Interpretative Essay. London: Bloomsbury Publishing. 
Chetkovich, Carol A., and Frances Kunreuther. 2007. From the Ground up: Grassroots Organizations Making Social Change. Ithaca: Cornell University Press.

Commission of the European Communities. 2005. Council Regulation (EC) No 1698/2005 Governing the Rural Development Regulation (RDR) 2007-2013. Brussels: CEC.

Commission of the European Communities. 2008. Council Directive on Implementing the Principle of Equal Treatment between Persons Irrespective of Religion or Belief, Disability, Age or Sexual Orientation. COM (2008) 426 Final 2008/0140 (CNS). Brussels: CEC.

Danius, Sara, Stefan Jonsson, and Gayatri Chakravorty Spivak. 1993. An Interview with Gayatri Chakravorty Spivak. Boundary 20: 24-50. [CrossRef]

Donaghy, Tahnya Barnett. 2004. Mainstreaming: Northern Ireland's participative-democratic approach. Policy and Politics 32: 49-62. [CrossRef]

Eide, Elisabeth. 2010. Strategic Essentialism and Ethnication Hand in Glove? Nordicom Review 31: 63-78. [CrossRef]

Equality Commission Northern Ireland. 2011. The Gaps between GB and NI Equality Law: A Briefing Note. Belfast: ECN. Fuss, Diana. 1989. Essentially Speaking. New York: Routledge.

Gerth, H. H., and C. W. Mills. 1946. From Max Weber: Essays in Sociology. Oxford: Oxford University Press.

Gimpel, James G., and J. Celeste Lay. 2008. Political Socialization and Reactions to Immigration-Related Diversity in Rural America. Rural Sociology 73: 180-204. [CrossRef]

Gormley, William T., Jr., and Helen Cymrot. 2006. The strategic choices of child advocacy groups. Nonprofit \& Voluntary Sector Quarterly 35: 102-22.

Guo, Chao. 2007. When government becomes the principal philanthropist: The effect of public funding on patterns of nonprofit governance. Public Administration Review 67: 456-71. [CrossRef]

Guo, Chao, and Gregory D. Saxton. 2010. Voice-in, voice-out: Constituent participation and non-profit Advocacy. Nonprofit Policy Forum 1: article 5. Available online: http://www.bepress.com/npf/vol1/iss1/5 (accessed on 26 November 2016).

Hacking, Ian. 1999. The Social Construction of What? Cambridge: Harvard University Press.

Hasenfeld, Yeheskel, and Benjamin Gidron. 2005. Understanding multi-purpose hybrid voluntary organisations: The contributions of theories on civil society, social movements and non-profit organisations. Journal of Civil Society 1: 97-112. [CrossRef]

Her Majesty's Stationery Office. 2010. Equality Act. London: Her Majesty's Stationery Office, Crown publications.

Irwin, Enny, Ruth McAreavey, and Niall Murphy. 2014. The Social and Economic Mobility of Ethnic Minority Communities in Northern Ireland. York: Joseph Rowntree Foundation.

Knox, Colin. 1996. The emergence of power sharing in Northern Ireland: Lessons from local government. The Journal of Conflict Studies 16: 7-29.

Lewis, Helen. 2006. Racism and sectarianism: Two sides of the same coin. The International Journal of Diversity in Organisations, Communities and Nations 6: 27-36.

Martin, Brian, and Evelleen Richards. 1995. Scientific knowledge, controversy, and public decision-making. In Handbook of Science and Technology Studies. Edited by Sheila Jasanoff, Gerald E. Markle, James C. Peterson and Trevor Pinch. Newbury Park: Sage, pp. 506-26.

Massey, Doreen. 2004. Geographies of responsibility. Geografiska Annaler: Series B, Human Geography 86: 5-18. [CrossRef]

McAreavey, Ruth. 2012. Resistance or Resilience? Tracing the Pathway of Recent Arrivals to a 'New' Rural Destination. Sociologia Ruralis 52: 488-507. [CrossRef]

McAreavey, Ruth. forthcoming. Migration to Rural and Peripheral Destinations. London: Routledge.

McCall, Cathal, and Arthur Williamson. 2001. Governance and Democracy in Northern Ireland: The Voluntary and Community Sector after the Agreement. Governance: An International Journal of Policy, Administration and Institutions 14: 363-83. [CrossRef]

Monaghan, Mark. 2009. The complexity of evidence: Reflections on research utilisation in a heavily politicised policy area. Social Policy \& Society 9: 1-12.

Monaghan, Mark. 2010. Adversarial Policies and Evidence Utilization: Modeling the Changing Evidence and Policy Connection. German Policy Studies 6: 17-52.

Mosley, Jennifer E. 2011. Institutionalization, privatization, and political opportunity: What tactical choices reveal about the policy advocacy of human service nonprofits. Nonprofit E Voluntary Sector Quarterly 40: 435-57. 
Mosley, Jennifer E. 2012. Keeping the Lights on: How Government Funding Concerns Drive the Advocacy Agendas of Nonprofit Homeless Service Providers. Journal of Public Administration Research and Theory 22: 841-66. [CrossRef]

Narayan, Uma. 1998. Essence of Culture and a Sense of History: A Feminist Critique of Cultural Essentialism. Hyparia 13: 86-106. [CrossRef]

Northern Ireland Council for Ethic Minorities. n.d. Briefing Paper on the Formal Review of the Race Relations (NI) Order 1997. Belfast: NICEM.

Northern Ireland Statistics and Research Agency. 2010. Mid-Term Evaluation of the Northern Ireland Rural Development Programme (NIIRDP) 2007-2013. Final Report. Belfast: NISRA.

Northern Ireland Statistics and Research Agency. 2013. Census 2011: Detailed Characteristics for Northern Ireland on Ethnicity, Country of Birth and Language. Statistics Bulletin Census 2011 (2011 Census KS212NI). Belfast: NISRA.

Nussbaum, Martha C. 1995. Objectification. Philosophy and Public Affairs 24: 249-91. [CrossRef]

Organisation for Economic Co-Operation and Development. 2006. DAC Guidelines and Reference Series Applying Strategic Environmental Assessment: Good Practice Guidance for Development Co-Operation. Paris: OECD.

Phillips, Anne. 2010. What's wrong with Essentialism? Distinktion: Scandinavian Journal of Social Theory 11: 47-60. [CrossRef]

Radaelli, Claudio M., and Anne Meuwese. 2010. Better Regulation in Europe. Between public management and regulatory reform. Public Administration Review 87: 639-54. [CrossRef] [PubMed]

Roginsky, Sandrine, and Sally Shortall. 2009. Civil society as a contested field of meanings. International Journal of Sociology and Social Policy 29: 473-87. [CrossRef]

Saraceno, Elena. 2013. Disparity and Diversity: Their Use in EU Rural Policies. Sociologia Ruralis 53: $331-48$. [CrossRef]

Shortall, Sally. 2012. The Role of Subjectivity and Knowledge Power Struggles in the Formation of Public Policy. Sociology 4: 1088-103. [CrossRef]

Shortall, Sally. 2013. Sociology, knowledge and evidence in rural policy making. Sociologia Ruralis 53: $265-71$. [CrossRef]

Shortall, Sally. 2014. Gender mainstreaming and the Common Agricultural Policy Gender Place and Culture. A Journal of Feminist Geography 22: 717-30. [CrossRef]

Shortall, Sally, and Roisin Kelly. 2001. Gender Proofing CAP Reforms. Cookstown: The Rural Community Network NI.

Skocpol, Theda. 2004. APSA Presidential Address: Voice and Inequality: The Transformation of American Civic Democracy. Perspectives on Politics 2: 3-20. [CrossRef]

Spivak, Gayatri Chakravorty. 1988. Subaltern Studies: Deconstructing Historiography. In In Other Worlds: Essays in Cultural Politics. Edited by R. Guha and Gayatri C. Spivak. Oxford: Oxford University Press, pp. 197-221.

Spivak, Gayatri Chakravorty. 1985. 'Race', Writing and Difference. Critical Inquiry 12: 243-61. [CrossRef]

Stone, Alison. 2004. Essentialism and Anti-Essentialism in Feminist Philosophy. Journal of Moral Philosophy 1: 135-53. [CrossRef]

The Executive Office. 2015. Racial Equality Strategy 2015-2015. Belfast: Office of the First Minister and Deputy First Minister for The Executive Office.

Wallace, Alison, Ruth McAreavey, and Karl Atkin. 2013. Poverty and Ethnicity in Northern Ireland. York: Joseph Rowntree Foundation.

Wallace Consulting. 2011. Programme for Cohesion, Sharing and Integration Consultation Analysis. Craigavon: Wallace Consulting.

(C) 2017 by the authors. Licensee MDPI, Basel, Switzerland. This article is an open access article distributed under the terms and conditions of the Creative Commons Attribution (CC BY) license (http://creativecommons.org/licenses/by/4.0/). 